\title{
THE IMPACT OF INFLATION UNCERTAINTY ON INTEREST RATES IN THE UK
}

\author{
Hakan Berument*
}

\begin{abstract}
This paper assesses the effect of expected inflation and inflation risk on interest rates within the Fisher hypothesis framework. Autoregressive Conditional Heteroscedastic models are used to estimate the conditional variability of inflation as a proxy for risk. With the UK quarterly data from 1958:4 to 1994:4, we found that both the expected inflation and the conditional variability of inflation positively affect the UK three-month Treasury-bill rate.
\end{abstract}

\section{INTRODUCTION}

Various studies have examined how the inflation risk affects the inflation rate (Cukierman and Wachtel, 1979; Ball and Cecchetti, 1990; Holland, 1993b, 1995) employment (Hafer, 1986; Holland, 1986) and output (Froyen and Waud, 1987; Holland, 1988) as measures of economic activity. This paper looks at the relationship between inflation risk and interest rates within the Fisher hypothesis framework. We find that inflation risk as well as the expected inflation positively affect the interest rates for the UK in the period from 1958:4 to 1994:4. Most scholars recognize the relationship between inflation risk and interest rates; however, few studies provide concrete applications and empirical evidence of this association. This paper provides empirical evidence that there is a positive relationship between those two variables for the UK within the Fisher hypothesis framework.

This study focuses on the UK for several reasons. First, the UK has had a sizable variation in its inflation rate, which makes it easier to detect a possible relationship between inflation uncertainty and interest rate. Second, the earlier literature on inflation risk, notably Engle (1982), provides us with a model with which to compare our findings with the earlier studies on the UK. The positive relationship between inflation risk and interest rates is particularly important for periods when governments attempt to decrease inflation. If deflationary policies are perceived as non-credible, the expected inflation will change less than the realized inflation. This will increase the forecast error, and hence the inflation risk. If the inflation risk affects the interest rates, this might be an alternative transmission mechanism that could explain how contractionary monetary policies decrease the output level, and this is our third reason.

* Bilkent University, Ankara, Turkey 
We used the Fisher hypothesis as a benchmark when we tested the existence of a relationship between interest rates and inflation risk. The Fisher hypothesis suggests that there is a relationship between interest rates and expected inflation, or between inflation and interest rates (see Fama, 1975; Fama and Gibbons, 1982; Mishkin, 1992; Mishkin and Simmons, 1995). The relationship between interest rates and (expected) inflation is found in several countries, including Canada, the United Kingdom and the United States. This study explicitly models the time varying inflation risk and incorporates the risk into the relationship between interest rates and expected inflation.

The effect of inflation uncertainty on interest rate is not well defined in the literature. Juster and Wachtel (1972a, 1972b) and Juster and Taylor (1975) argue that if the money income variability does not match the variability of inflation, then the real income variability will be affected by the inflation variability. This leads to decreased consumer confidence. Hence, there will be a positive relationship between inflation uncertainty and saving when consumers seek to protect themselves against inflation. These authors provide empirical evidence for this positive relationship. Hahn (1970) also sets up a theoretical foundation for this relationship. Therefore, this line of research suggests that there is a negative relationship between inflation uncertainty and interest rates within the loanable fund theory. On the other hand, Markowitz's (1952) portfolio theory suggests that risk-averse investors must be compensated with higher returns for a higher risk. The reason is that unanticipated inflation decreases the real return of the $t$-bill rate. Higher conditional variability of inflation creates risk on real $t$ bill returns. Therefore, inflation risk should be positively correlated with interest rates. Fama (1975), Fama and Schwert (1977), Mishkin (1981), Fama and Gibbons (1982) and Chan (1994) provide empirical evidence for the positive relationship between inflation expectation variation and the $t$-bill rates under different specifications such as asset pricing models or term structure of interest rates. Hence, the overall effect of inflation uncertainty on interest rate is not known a priori.

In order to model inflation uncertainty, we assume that inflation follows an autoregressive process and that the conditional mean is equal to the expected inflation. The square root of the conditional variability of that process is modelled as a Generalized Autoregressive Conditional Heteroscedastic process, and the square root of the conditional variability of inflation is used as a measure of risk. This study finds that both the conditional mean and variance of inflation are positively correlated with the UK $t$-bill rate.

The plan of this paper is as follows. The next section develops and outlines the methodology. The model is then estimated using UK quarterly data. The findings are reported in Section III and then these findings are summarized in the final section.

\section{Method AND Discussion}

This section introduces the model used to test the relation between inflation risk and interest rates. We first discuss the inflation equation. Next, we model the 
conditional variability of inflation; and lastly we specify the interest rate equation.

Following Engle (1982), we assume that the inflation rate at time $t, \pi_{t}$, is affected by both its $s$ lagged values and the lagged value of the real wage $(w-p)_{t-1}$. The reason for this specification is that within the Phillips curve framework, a higher real wage may accelerate inflation. Furthermore, inflation itself may follow an autoregressive process. ${ }^{1}$ Hence, we model the inflation equation as:

$$
\pi_{t}=i_{0}+\sum_{j=1}^{s} i_{j} \pi_{t-j}+i_{w}(w-p)_{t-1}+\varepsilon_{t}
$$

where $i_{j}$ is the coefficient of the $j^{\text {th }}$ lag of the inflation rate, $i_{w}$ is the coefficient of the lagged value of the real wage and $\varepsilon_{t}$ is the discrete-time real valued stochastic process with a normal conditional distribution given by:

$$
\varepsilon_{t} / \Omega_{t-1} \sim N\left(0, h_{t}\right)
$$

Here, $\Omega_{t-1}$ is the information set that includes all information available at time $t-1$. The expected value of $\varepsilon_{t}$ is zero, and the conditional variance of $\varepsilon_{t}$ given the information set at time $t-1$ is $h_{t}$. Therefore, the conditional expectation of the inflation rate at time $t$, given the information set at time $t-1$, is:

$$
E_{t}\left(\pi_{t} / \Omega_{t-1}\right)=i_{0}+\sum_{j=1}^{s} i_{j} \pi_{t-j}+i_{w}(w-p)_{t-1} .
$$

Note that the variance of $\varepsilon_{t}, h_{t}$, is not assumed to be constant. If $h_{t}$ is time invariant, then the conditional variance cannot be used to measure the time varying risk. Engle (1982) introduces the Autoregressive Conditional Heteroscedastic (ARCH) model which allows one to estimate the time varying conditional variances. He assumes that $h_{t}$ depends upon the past realization of the square of the error terms:

$$
h_{t}=d_{0}+\sum_{j=1}^{p} d_{j} \varepsilon_{t-j}^{2} .
$$

The time varying variance may follow an autoregressive process itself. Bollerslev (1986) introduced the Generalized Autoregressive Conditional Heteroscedastic

\footnotetext{
${ }^{1}$ Here, it is assumed that the inflation equation has constant coefficients. It is possible that coefficients can vary. Evans (1991) defines two types of uncertainty: uncertainty about the short-term prospect of inflation-measured with the conditional variance of inflation equation residuals - and uncertainty about the long-term prospect of inflation - measured with the changing coefficients of the inflation equation. Evans (1991) finds evidence for the US that uncertainty due to changing coefficients could be important and he finds that there is a relationship between the level of inflation and long-run inflation uncertainty. There are two reasons that we did not allow changing coefficients of the inflation equation. The first one is that we are interested in the effect of the short run prospect of the inflation uncertainty on interest rate. Three-month treasury bill rates are used as interest rates, and that is one period in our analysis since we used quarterly data. Long-run uncertainty on inflation may not be relevant to the short run interest rates. For the second reason, we observe the effect of inflation uncertainty on another variable (three-month treasury bill rates) rather than the level of that variable (inflation). Incorporating the coefficient uncertainty on inflation equation to the interest rate equation is not well defined (see, Harvey, 1989). Nevertheless, incorporating that effect is another avenue to pursue, but it is beyond the scope of this article.
} 
$(\mathrm{GARCH})$ process, which extends the ARCH model such that $h_{t}$ is also a function of lagged values of $h_{t}$. Under a GARCH specification, the conditional variance, $h_{t}$, could be modelled as:

$$
h_{t}=d_{0}+\sum_{j=1}^{p} d_{1 j} \varepsilon_{t-j}^{2}+\sum_{j=1}^{q} d_{2 j} h_{t-j} .
$$

Bollerslev's specification requires both that $\sum_{j=1}^{p} d_{1 j}+\sum_{j=1}^{q} d_{2 j}$ be less than one and that all $d_{0}, d_{1 j}$ s and $d_{1 j}$ s be positive, as sufficient conditions to satisfy both the stationarity and non-negativity of the conditional variances.

We estimate the following equation to test the effects of expected inflation, $\pi_{t}^{e}$, and inflation risk, $\sqrt{h_{t}}$, on interest rates:

$$
R_{t}=c_{0}+c_{\pi} \pi_{t}^{e}+c_{h} \sqrt{h_{t}}+\eta_{t},
$$

where $R_{t}$ is the interest rate, $\eta_{t}$ is white noise process at time $t$, and $c_{0}$ is the intercept term. We will use equation (3) to measure the expected inflation. We expect $c_{\pi}$ to be positive. The sign of $c_{h}$ indicates the estimated effect of inflation uncertainty on the interest rate. Markowitzian portfolio theory predicts $c_{h}$ to be positive. If agents want to protect themselves against uncertain real income, which is associated with inflation uncertainty, then savings may increase and interest rates might be lowered; hence, $c_{h}$ will be negative.

\section{EMPIRICAL EVIDENCE AND DISCUSSION}

This section presents the empirical evidence from the UK for equations (1, 4 (or 5) and 6). Empirical evidence suggests that both inflation risk and expected inflation positively affect the $t$-bill rate. We used quarterly data from 1958:4 to 1994:4 to estimate the basic model of this paper. However, the data for the real wage series is not available for the full sample; hence our sample starts from 1963:2 for the regressions where the real wage is used as an explanatory variable in the inflation equation. The real wage is measured as the log difference of the average of weekly wage and CPI, inflation is the first log difference of consumer price indices from period $t$ to $t+1$, and the interest rate is the three-month treasury bill rate. The series for the money wage is taken from the OECD Main Economic Indicators. All other data is from the International Monetary FundInternational Financial Statistics.

Before estimating the complete model, we tested for the presence of an $\mathrm{ARCH}$ effect. We first estimated the inflation equation. Inflation is specified as a regular autoregressive process; then we included the lagged value of the real wage as an additional explanatory variable. The order of the autoregressive process is determined using both the Akaike and Schwartz-Bayesian information criteria. Both sets of criteria indicate that the inflation equation can be represented as a function of its $1^{\text {st }}, 4^{\text {th }}$ and $5^{\text {th }}$ lags where the $4^{\text {th }}$ and $5^{\text {th }}$ lag values of inflation may capture seasonal effects (see Enders, 1995, p. 112, for a discussion of the modelling of seasonal data). The order of lag values of inflation is the same as in Engle's original model. When we estimated the model including the real wage, the estimated coefficients of the lagged values of 
inflation rates are statistically significant. ${ }^{2}$ The real wage is not statistically significant (not reported). However, we decided to retain the real wage in order to follow the Engle model.

Next, we tested for the presence of an ARCH effect by using the Lagrange multiplier test outlined by Engle (1982). The squared residuals of the inflation equation were regressed then on its $1^{\text {st }}, 4^{\text {th }}, 8^{\text {th }}, 12^{\text {th }}$ and $16^{\text {th }}$ lags. Then we calculated $T R^{2}$ values, where $T$ is the number of observations in the sample and $R^{2}$ is the proportion of variances explained by the explanatory variables; $T R^{2}$ values were $22 \cdot 761,41 \cdot 001,44 \cdot 370,45 \cdot 236$ and $45 \cdot 244$, respectively. The critical values for $\chi^{2}$ were $3.84,9.49,15.51,21.03$ and 26.30 , respectively. Hence, we reject the null hypothesis that there is no ARCH effect.

After confirming the existence of the ARCH effect, following Engle (1982), we first modelled the inflation risk as an ARCH(4) process. Specifically, we modelled the conditional variability equation as:

$$
h_{t}=d_{0}+d_{1}\left(0 \cdot 4 \varepsilon_{t-1}^{2}+0 \cdot 3 \varepsilon_{t-2}^{2}+0 \cdot 2 \varepsilon_{t-3}^{2}+0 \cdot 1 \varepsilon_{t-4}^{2}\right) .
$$

The reason for choosing a two-parameter conditional variance function is to guarantee the non-negativity and stationarity constraints that might not be satisfied if the unrestricted estimating equation were used. For the ARCH(4) process, the necessary and sufficient conditions for the two constraints to be satisfied are $d_{0}>0$ and $0<d_{1}<1$.

We used the Full Information Maximum Likelihood (FIML) method to estimate sets of equations. Pagan (1984) argued that using regressors that are generated from a stochastic model in the estimation of a structural equation can give biased estimates for the parameters' standard errors. Furthermore, Pagan and Ullah (1988) suggest using the FIML method to avoid the possibility of biased estimates. The estimates we obtained are reported in Table 1. Since the FIML method is used to estimate the model, these estimates are consistent.

The preliminary results on inflation equation, $\mathrm{ARCH}$ specification and Fisher equation are encouraging. The estimated coefficients for all lag values of inflation are statistically significant. These coefficients have signs equivalent to Engle's for the inflation equation. The estimated coefficient for the real wage is positive, suggesting that a higher real wage accelerates inflation; however, the statistical evidence is weak as suggested by the $t$-ratio. Moreover, the estimated coefficient for the ARCH effect $(0.647688)$ is statistically significant and is less than one. This result suggests that the variability dies out as expected. There is also a positive and statistically significant relationship between expected inflation and the interest rate. More importantly, there is a positive and significant relationship between the interest rate and the measure of inflation risk. Here conditional variance assesses the forecast error dispersion that agents make for the level of inflation. If the agents make more mistakes on forecasting the inflation, then the conditional variance will go up. On average, the standard error of inflation equation is 1.12315 (unconditional standard error of inflation equation: $\sqrt{0.445352 /(1-0 \cdot 647688})$. If the agents start to make more mistakes on average, then the unconditional

\footnotetext{
${ }^{2}$ The level of significance is $5 \%$, unless otherwise mentioned.

(C) Scottish Economic Society 1999
} 
standard error increases. If the unconditional variance increases by $0 \cdot 1$ (from 1.12315 to 1.22315 ), then the $t$-bill rate will increase by 0.266 .

The model reported in Table 1 restricts the weights of the lagged values of the residual squares. Following Bollerslev (1986) and using the procedure underlined by Enders (1995), we modelled the inflation conditional variability as a $\operatorname{GARCH}(2,1)$ process after trying various specifications. The results are reported for the $\operatorname{GARCH}(2,1)$ specification in Table 2. We observed significant coefficients for the lagged variables in the inflation equation. However, the coefficient of the real wage is still not significant. Hence, the estimates reported in Table 2 for the inflation equation are parallel to the ones reported in Table 1. The conditional variability equation has positive coefficients and their sum is less than one; i.e., Bollerslev's sufficient condition is satisfied. Lastly, the coefficients of both expected inflation and inflation risk are positive and statistically significant in the Fisher equation.

Note that in both sets of results, the real wage could not explain the behaviour of interest rates at a statistically significant level. We therefore drop the real wage from the regression analysis and then we can extend our sample size. We report the estimates of the new model by using quarterly data from 1958:4 to 1994:3 in Table 3. Table 3 gives more efficient estimates than the estimates reported in Tables 1 and 2 because it excludes a variable that does not explain the behaviour of inflation and uses a longer data set. There is still a significant positive relationship between inflation risk and the $t$-bill rate. All coefficients of interest are significant.

The positive relationship between $t$-bill rate and inflation expectation as well as the positive relationship between $t$-bill rate and inflation uncertainty are documented in the literature. For the interest rate and inflation relationship one may look at Fama and Gibbons (1982), Mishkin (1992) and Mishkin and Simmons (1995) and references cited therein. The positive relationship between interest rate and inflation risk is also documented in the literature. Fama (1975), Fama and Schwert (1977), Barnea, Daton and Lakonishok (1979), Mishkin (1981), Fama and Gibbons (1982) and Chan (1994) offer evidence for the US, and Kandel, Ofer and Sarig (1996) find the positive risk premium for Israel. Even if these papers use different approaches such as asset pricing models or the term structure of interest rates in order to find this relationship, it is important to note that our results on the positive inflation risk premium are parallel to theirs.

\section{Specification tests}

Note that when all coefficients of the $h_{t}$ equation are positive, the sufficient condition that all conditional variances be positive is satisfied. We tested to see whether any shock to inflation risk dies out. The sum of the coefficients for the autoregressive process is 0.984389 , which is almost equal to one. Hence the model suggests that any shock to the variability of inflation does not die out, but rather remains permanent. This result parallels the findings of other studies. For example, Engle (1982) observed 0.955 for UK inflation, while Engle, Lilien and Robins (1987) estimated 1.64 for their ARCH specification of US inflation. 
TABLE 1

The estimates of the complete model with an ARCH(4) specification

\begin{tabular}{|c|c|c|c|c|c|c|c|c|c|c|}
\hline$\pi_{t}$ & $\begin{aligned}= & 0.204466 \\
& 0.173955 \\
& 1.1754\end{aligned}$ & $\begin{array}{c}+0.572985 \\
0.100118 \\
5.72308\end{array}$ & $\pi_{t-1}$ & $\begin{array}{c}+0.651708 \\
0.068215 \\
9.55379\end{array}$ & $\pi_{t-4}$ & $\begin{array}{c}-0.40467 \\
0 \cdot 101632 \\
-3.98174\end{array}$ & $\pi_{t-5}$ & $\begin{array}{c}+0.000904 \\
0.003684 \\
0.24528\end{array}$ & $(w-p)_{t-1}$ & $+\varepsilon_{t}$ \\
\hline$h_{t}$ & $\begin{aligned}= & 0.445352 \\
& 0.156595 \\
& 2.84398\end{aligned}$ & $\begin{array}{c}+0.647688 \\
0.259373 \\
2.49712\end{array}$ & \multicolumn{4}{|c|}{$\left(0 \cdot 4 \varepsilon_{t-1}^{2}+0 \cdot 3 \varepsilon_{t-2}^{2}+0 \cdot 2 \varepsilon_{t-3}^{2}+0 \cdot 1 \varepsilon_{t-4}^{2}\right)$} & & & & \\
\hline$R_{t}$ & $\begin{aligned}= & 5.131263 \\
& 1.040229 \\
& 4.93282\end{aligned}$ & $\begin{array}{c}+0.695897 \\
0.259864 \\
2.67793\end{array}$ & $\pi_{t}^{e}$ & $\begin{aligned}+2.656164 \\
1 \cdot 137472 \\
2.33515\end{aligned}$ & $\sqrt{h_{t}}$ & $+\eta_{t}$ & & & & \\
\hline System & $-241 \cdot 516$ & & & & & & & & & \\
\hline
\end{tabular}

Notes:

The first number under an estimated coefficient is the standard error, the second is the $t$-ratio.

$\pi_{t}$ is the inflation rate, $(w-p)_{t-1}$ is the lag value of the real wage, $\pi_{t}^{e}$ is the conditional mean of the inflation, $h_{t}$ is the conditional variance of the inflation, $R_{t}$ is the t-bill rate, $\varepsilon_{t}$ is the residual of the inflation equation and System is the value of the log likelihood function. 
TABLE 2

The estimates of the complete model with the $\operatorname{GARCH}(2,1)$ specification

\begin{tabular}{|c|c|c|c|c|c|c|c|c|c|c|}
\hline$\pi_{t}$ & $\begin{aligned}= & 0 \cdot 36116 \\
& 0 \cdot 086765 \\
& 4 \cdot 16252\end{aligned}$ & $\begin{array}{c}+0.589189 \\
0.067562 \\
8 \cdot 72067\end{array}$ & $\pi_{t-1}$ & $\begin{array}{c}+0.658159 \\
0.051231 \\
12 \cdot 84686\end{array}$ & $\pi_{t-4}$ & $\begin{array}{c}-0.45615 \\
0.065192 \\
-6.99704\end{array}$ & $\pi_{t-5}$ & $\begin{array}{r}-0 \cdot 00292 \\
0 \cdot 00606 \\
-0.48118\end{array}$ & $(w-p)_{t-1}$ & $+\varepsilon_{t}$ \\
\hline$h_{t}$ & $\begin{aligned}= & 0.070788 \\
& 0.029593 \\
& 2 \cdot 39208\end{aligned}$ & $\begin{array}{c}+0.042927 \\
0.019942 \\
2.15263\end{array}$ & $\varepsilon_{t-1}^{2}$ & $\begin{array}{c}+0.193849 \\
0.189472 \\
1.0231\end{array}$ & $h_{t-1}$ & $\begin{array}{c}+0.716364 \\
0.186387 \\
3.84342\end{array}$ & $h_{t-2}$ & & & \\
\hline$R_{t}$ & $\begin{array}{c}=-0.08822 \\
4.461546 \\
-0.01977\end{array}$ & $\begin{array}{c}+0.551928 \\
0.208576 \\
2.64618\end{array}$ & $\pi_{t}^{e}$ & $\begin{array}{c}+7.724463 \\
3.834745 \\
2.01434\end{array}$ & $\sqrt{h_{t}}$ & $+\eta_{t}$ & & & & \\
\hline System & $-225 \cdot 684$ & & & & & & & & & \\
\hline
\end{tabular}

Notes:

The first number under an estimated coefficient is the standard error, the second is the $t$-ratio.

$\pi_{t}$ is the inflation rate, $(w-p)_{t-1}$ is the lag value of the real wage, $\pi_{t}^{e}$ is the conditional mean of the inflation, $h_{t}$ is the conditional variance of the inflation, $R_{t}$ is the $t$-bill rate, $\varepsilon_{t}$ is the

residual of the inflation equation and System is the value of the log likelihood function. 
TABLE 3

The estimates of the complete model with a $\operatorname{GARCH}(2,1)$ specification without the real wage

\begin{tabular}{|c|c|c|c|c|c|c|c|}
\hline$\pi_{t}$ & $\begin{aligned}= & 0.171045 \\
& 0 \cdot 106336 \\
& 1.60854\end{aligned}$ & $\begin{array}{c}0.575877 \\
0.061826 \\
9.31453\end{array}$ & $\pi_{t-1}$ & $\begin{array}{c}+0.544130 \\
0.046448 \\
11.71477\end{array}$ & $\pi_{t-4}$ & $\begin{array}{r}-0.28397 \\
0.08192 \\
-3.46647\end{array}$ & $\pi_{t-5}$ \\
\hline$h_{t}$ & $\begin{aligned}= & 0 \cdot 046571 \\
& 0 \cdot 012261 \\
& 3 \cdot 79821\end{aligned}$ & $\begin{array}{c}0.043348 \\
0.01187 \\
3.65191\end{array}$ & $\varepsilon_{t-1}^{2}$ & $\begin{array}{c}0.371237 \\
0.221161 \\
1.67858\end{array}$ & $h_{t-1}$ & $\begin{array}{c}+0.569804 \\
0.214103 \\
2.66135\end{array}$ & $h_{t-2}$ \\
\hline$R_{t}$ & $\begin{array}{c}=-1.29063 \\
1.320854 \\
-0.97712\end{array}$ & $\begin{array}{c}0.719413 \\
0.175384 \\
4.10194\end{array}$ & $\pi_{t}^{e}$ & $\begin{array}{c}+7 \cdot 677617 \\
1.391202 \\
5.51869\end{array}$ & $\sqrt{h_{t}}$ & $+\eta_{t}$ & \\
\hline System & $-264 \cdot 886$ & & & & & & \\
\hline
\end{tabular}

Notes:

The first number under an estimated coefficient is the standard error, the second is the $t$-ratio.

$\pi_{t}$ is the inflation rate, $\pi^{e}$ is the conditional mean of the inflation, $h_{t}$ is the conditional variance of the inflation, $R_{t}$ is the t-bill rate, $\varepsilon_{t}$ is the residual of the inflation equation and System is the value of the log likelihood function. 
As a second test for the model's specification, we tested whether there is a unit root in the residuals of the Fisher equation. If there is a long-run relationship among the $t$-bill rates, the conditional expected inflation and the conditional variability of inflation, the residuals should be stationary. We performed various unit root tests on the residuals of the Fisher equation. The Dickey and Fuller test gives $-12 \cdot 10122$, the Augmented Dickey and Fuller test yields -7.49138, the Phillips and Perron test result is -132.79838 , and the Stock and Watson test yields -128.89080 . The critical values are -3.51 for both the Dickey and Fuller and the Augmented Dickey and Fuller tests, -20.4935 for the Phillips and Perron, and -20.6 for the Stock and Watson tests. All the test statistics reject the unit root. These results reveal the same long-run relationship that Mishkin (1992) found for the Fisher model.

Lastly, positive and negative innovations in the inflation equation may affect the inflation uncertainty differently. GARCH models assume that only the magnitude and not the sign of the unanticipated change in the inflation equation determines the volatility; i.e., it is the squared innovation $\varepsilon_{t-1}$, that affects $h_{t}$ so that $h_{t}$ is invariant of the sign of the $\varepsilon_{t-1}$ s. Following Nelson (1991)'s Exponential-GARCH modelling, we incorporated this asymmetry into the model. However, the empirical evidence could not suggest the presence of this asymmetry effect in a statistically significant fashion.

\section{SUMMARY}

Inflation uncertainty may affect interest rates. The current advances in econometric methods allow us to estimate the conditional variability of inflation as a proxy for risk. In this paper, we introduce the effect of conditional variability into the Fisher equation. We found first, that conditional variability positively affects the UK three-month Treasury-bill rate. This study also confirms the long-run relationship among the $t$-bill rate, expected inflation and inflation risk that was reported in previous studies for the $t$-bill rate and expected inflation. This study has a very important implication for governments trying to decrease inflation. If the deflationary policies are not considered credible by the public, the expected inflation will change less than the level of inflation, and this will increase the inflation risk. This paper shows that higher inflation risk increases the interest rates, and that might be another transmission mechanism that could explain how deflationary policies decrease output. Controlling inflation risk by other means may decrease the loss generated by lowering inflation. Further research is necessary to explore whether inflation risk affects other variables such as credit and exchange rates, which ultimately affect measures of economic activity.

\section{ACKNOWLEDGEMENTS}

The author wishes to thank Anita Akkaş, Laura Feitzinger Brown, Anwar ElJawhari, Nuray Güner, Richard Froyen, Miguel Herce, Michael Salemi and an anonymous referee for their comments. 


\section{REFERENCES}

BALl, L. and CECCHETti, S. (1990). Inflation uncertainty at short and long horizons. Brookings Papers on Economic Activity pp. 215-54.

BARNEA, A., DATON, A. and LAKONISHOK, J. (1979). The effect of price level uncertainty on the determination of interest rates: Some empirical evidence. Southern Economic Journal, pp. 609-14.

BOLlersleV, T. (1986). Generalized autoregressive conditional heteroscedasticity. Journal of Econometrics, 31, pp. 307-27.

CHAN, L. K. C. (1994). Consumption, inflation risk, and real interest rates: an empirical analysis. Journal of Business, 67, pp. 69-96.

Cukierman, A. and Wachtel, P. (1979). Differential inflationary expectations and the variability of the rate of inflation. American Economic Review, pp. 595-609.

Enders, W. (1995). Applied Econometric Time Series. John Wiley, New York.

ENGLE, R. (1982). Autoregressive conditional heteroscedasticity with estimates of the variance of United Kingdom inflation. Econometrica, 50, pp. 987-1007.

ENGLE, R., LILIEN, D. and RoBINS, R. (1987). Estimating time varying risk premium in the term structure: The ARCH-M Model. Econometrica, 55, pp. 391-407.

EvANS, M. (1991). Discovering the link between inflation rates and inflation uncertainty. Journal of Money, Credit and Banking, 23, pp. 169-84.

FAMA, E. (1975). Short term interest rates as predictor of inflation. American Economic Review, 65, pp. 269-82.

FAMA, E. and GIBBONS, M. (1982). Inflation, real returns and capital investment. Journal of Monetary Economics, 9, pp. 297-323.

FAMA, E. and SCHWERT, G. (1977). Asset returns and inflation. Journal of Financial Economics, 5, pp. 115-46.

FISHER, I. (1907). The Rate of Interest. New York: Macmillan.

FROYEN, R. and WAUD, R. (1987). An examination of aggregate price uncertainty in four countries and some implications for real output. International Economic Review, pp. $353-73$.

HAFER, R. W. (1986). Inflation uncertainty and a test of the Friedman hypothesis. Journal of Macroeconomics, pp. 365-72.

Hahn, F. H. (1970). Savings and uncertainty. Review of Economic Studies, 37, pp. 21-24.

Harvey, A. (1989). Forecasting, Structural Time Series Models and the Kalman Filter. Cambridge University Press, New York.

HoffMAN, D. (1987). Two-step generalized least squares estimators in multiequation generated regressor models. Review of Economics and Statistics, pp. $336-46$.

Holland, S. (1986). Wage indexation and the effect of inflation uncertainty on employment: An empirical analysis. American Economic Review, pp. 235-44.

Holland, S. (1988). Indexation and the effect of inflation uncertainty on Real GNP. Journal of Business, pp. 473-84.

Holland, S. (1993a). Uncertainty effects of money and the link between the inflation rate and inflation uncertainty. Economic Inquiry, pp. 43-54.

Holland, S. (1993b). Comment on inflation regimes and the sources of inflation uncertainty. Journal of Money, Credit and Banking, 25, pp. 514-20.

Holland, S. (1995). Inflation and uncertainty: test for temporal ordering. Journal of Money, Credit and Banking, 27, pp. 827-37.

JENSEN, D. W. (1989). Does inflation uncertainty affect output growth? Further evidence. Federal Reserve Bank of St. Louis Review, July/August.

Juster, F. T. and TAYLOR, D. (1975). Towards a theory of saving behavior. American Economic Review, 65, pp. 203-09.

Juster, F. T. and WACHTEL, P. (1972a). Inflation and the consumer. Brookings Papers, 1 , pp. $71-114$.

Juster, F. T. and WAChtel, P. (1972b). A note on inflation and the saving rate. Brookings Papers, 3, pp. 765-78.

KANDEL, S., OFER, A. and SARIG, O. (1996). Real interest rates and inflation: an ex-ante empirical analysis. The Journal of Finance, 60, pp. 205-25.

MARKowitz, H. M. (1952). Portfolio selection. Journal of Finance, pp. 77-91.

MishKIN, F. S. (1981). The real interest rate: an empirical investigation. CarnegieRochester Conference Series on Public Policy, 15, pp. 151-200.

(C) Scottish Economic Society 1999 
MishKin, F. S. (1992). Is the Fisher effect for real? Journal of Monetary Economics, 30, pp. $195-215$.

MishKin, F. S. and Simmons, J. (1995). An empirical investigation of the Fisher effect in Australia. NBER Working Paper, no. 5080.

Nelson, D. B. (1991). Conditional heteroscedasticity in asset returns. Econometrica, 45, pp. $347-38$.

PAGAN, A. (1984). Econometrics issues in the analysis of regressions with generated regressors. International Economic Review, pp. 221-47.

Pagan, A. and Ullah, A. (1988). The econometric analysis of a model with risk terms Journal of Applied Econometrics, pp. 87-105.

Date of receipt of final manuscript: 15 October 1998. 